\title{
Correction to: Microstructure and Oxidation Performance of TiAl-(Cr, Nb, Ta) Coatings Fabricated by Warm Spray and High-Velocity Oxy-Fuel Spraying
}

\author{
Judyta Sienkiewicz $^{1,2}$ (D) $\cdot$ Seiji Kuroda ${ }^{1} \cdot$ Hideyuki Murakami $^{1} \cdot$ Hiroshi Araki $^{1}$. \\ Maciej Giżyński ${ }^{3} \cdot$ Krzysztof J. Kurzydłowski $^{4}$
}

Published online: 4 March 2019

(C) ASM International 2019

\section{Correction to:}

J Therm Spray Tech (2019) 28:563-579

https://doi.org/10.1007/s11666-019-00837-5

The primary affiliation of author Judyta Sienkiewicz should be listed as: Research Center for Structural Materials, National Institute for Materials Science, Tsukuba-Shi,
Japan, and the secondary affiliation as: Institute of Armament Technology, Faculty of Mechatronics and Aerospace Military University of Technology, Warsaw, Poland.

Publisher's Note Springer Nature remains neutral with regard to jurisdictional claims in published maps and institutional affiliations.

The original article can be found online at https:// doi.org/10.1007/s11666-019-00837-5.

Judyta Sienkiewicz

judyta.sienkiewicz@wat.edu.pl

1 Research Center for Structural Materials, National Institute for Materials Science, 1-2-1, Sengen, Tsukuba-Shi, Ibaraki-ken 305-0047, Japan

2 Institute of Armament Technology, Faculty of Mechatronics and Aerospace, Military University of Technology, Urbanowicza 2, 00-908 Warsaw, Poland

3 Faculty of Materials Science and Engineering, Materials Design Division, Warsaw University of Technology, Woloska 141, 02-507 Warsaw, Poland

4 Faculty of Mechanical Engineering, Bialystok University of Technology, 45A, Wiejska Street, 15-351 Bialystok, Poland 